MCDSARE: 2020

\title{
International Multidisciplinary Scientific Conference on the Dialogue between Sciences \& Arts, Religion \& Education
}

\section{Religion as the single foundation of Science}

\author{
Ph.D. Spyridon I. Kakos (a)*, \\ * Corresponding author \\ (a) National Technical University of Athens (NTUA), Athens, Greece, skakos@hotmail.com.
}

\begin{abstract}
For centuries, science was considered as something radically different from religion. Yet, the foundations of true science are deeply religious in nature. This paper seeks to show how religion is the only foundation needed for the formulation of scientific theories, since it provides the core principles on which the building of exact sciences is based upon. Our need to understand the cosmos and our faith in us being able to do so, are the main prerequisites for conducting science; prerequisites that are derived from our belief in us being the sons of God and, thus, being able to read His mind. From its birth on 7 March 1277 up to today, science seems to be the only logical attitude of religious people towards the unknown cosmos.
\end{abstract}

Keywords: science; science philosophy; foundations of science; religion; axioms; scientific principles

\section{INTRODUCTION}

People see science as something different and many times at war with religion. Thus, many would be surprised to know that the foundations of science lie in religion per se. If someone wants to do science then he must first believe in some of the basic principles of religion. This is not a figure of speech, a metaphor or a symbolical aphorism, but a very practical truth. Only religion can offer the justification to do science. The religiousness of so many great scientists is not a random phenomenon that can be attributed to the norm of society back at the time, but a logical consequence of what religion teaches for humans and their relation to God and the cosmos. Once one understands the needs of the scientific method, it is evident that the very first steps of the scientific inquiry could never be taken inside a sterile atheistic (or even agnostic) environment, but only inside the womb of deep religious belief in God.

\section{PURPOSE OF THE STUDY}

The purpose of this study is to investigate the core foundations of science and its relationships with the relevant foundations of religion. The goal is to show that religion is not only compatible with science, but it is actually a fundamental prerequisite for science. Without religion, man would not be able to even start his exploration of the cosmos in a systematic way as per the scientific method. Science is not 
just another way of exploring the cosmos, but a logical consequence of religion when it comes to analyzing and understanding the universe.

\section{RESEARCH METHODS}

The problem under analysis was examined with the help of two tools: Philosophy and History of science. The latter was the tool that provided evidence for the way science has been evolving throughout centuries of human endeavour. This provided helpful insights of how scientific theories are formulated and how scientists think in order to create new scientific models for explaining the cosmos. The former was used to show why the philosophy of religion is the basic principle on which scientific research is based upon. By using specific logical arguments, it was shown that the basic principles of science are the basic beliefs of Christianity regarding the relationship between humans and God.

\section{FINDINGS}

The findings of the research clearly show that the principles used by exact science today are based on two basic Christian principles. The belief in the existence of God and the belief that we are part of Him (or that we can be part of Him). An analysis of how scientific theories are formed makes it obvious that these beliefs are the basic pre-requisites for conducting science and precede all other axiomatic assumptions needed for the formulation of any scientific theory.

\subsection{How science builds scientific theories}

Science builds theories to formulate models, which in turn explain (and predict) how the cosmos works. What we call "scientific method" uses various tools to build and verify or falsify hypotheses (e.g. statistical analysis) so as to create those models that explain the cosmos (Hanne Andersen, Brian Hepburn, 2015). These models do not exist in the void but are always part of general theories, which offer an overall understanding of how the cosmos operates. Scientists build these theories based on axioms or principles via the application of specific methods (e.g. logical induction). These principles are essentially the starting points on which the theory is based upon; there can be no theory without such principles, for even the simplest of theories must start from somewhere.

A note regarding nomenclature is of importance here. The term 'axiom' is mainly used in mathematics and geometry. The axioms of geometry are a good example (H. G. Forder, 1929). The infamous fifth axiom of Euclid is being taught around the world as the leading example of how axioms are used to build theories. Based on that and four more axioms, Euclid built his geometry, which dominated the world of mathematics for almost two thousand years up until very recently. When the time came to choose another axiom, different types of geometries emerged. All other sectors of science also have their own foundations, which are usually not called 'axioms' but 'principles'. The principle of the conservation of energy is a good such example. This principle is usually referred to as a 'law', which can be confusing. What is significant here is to know that in both physics and geometry, theories are based on specific foundation building blocks.

These building blocks are not proven propositions (in the absolute philosophical meaning of the term), but propositions which are accepted as correct based on intuition and strong indications. An axiom or an accepted principle is by definition something not proved. This does not mean however that there are not arguments in favor of accepting them. As it is logical to infer that you can only draw one parallel line from another line, it is also logical to say that energy is conserved in a system - even though we have not examined all the physical systems in the universe. This conclusion is based on evidence currently available, but these evidence are in any case circumstantial when compared to the vastness of space and all the possible systems that can exist in the cosmos. At the end, the conservation of energy is accepted on terms of faith that all the other systems we have not yet examined will continue to work like the systems we have. 
For the time being, the belief in that principle (or 'law') is an axiom that we have to adhere to, if we want to move to the next step of building the theory, while keeping in mind that in the next day some new evidence or logical arguments could prove that principle wrong.

Taking the above for grated, a serious implication becomes evident: It is easy to change theories. In case we change axioms/ principles, then the theories change as well. Examining some indicative - but highly representative - examples of theories will make that point more clear.

\subsubsection{From gravitational field to curved spacetime}

The planetary movements had for a long time been the subject of discussion among philosophers and scientists alike. Gravitation is one of the most significant phenomena that attracted the attention of humankind for ages. The two most influential theories for gravitation currently are, namely, Isaac Newton's Theory of Gravitation and Albert Einstein's General Theory of Relativity, which includes an alternative explanation of the gravitation phenomena (Tomas Kala, 2019). These theories offer the context to explain and understand why things appear to attract things and why planets move the way they do in the vast space. Both theories are essentially consisting of a set of assumptions that formulate the foundations of a selfconsistent explanation for the celestial phenomena we observe.

What is self-evident here is that no matter how we change the explanation, the observed phenomena ${ }^{1}$ stay the same. No matter what the theory is, apples keep on falling down on the ground. What changes is the explanation of the why (or how) this happens.

Newtonian mechanics explain the planetary movements on the basis of the existence of a gravitational field, which exerts power over all bodies placed inside it. To formulate that theory, one has to begin with properly defining the notions used, e.g. with the definition of the mass (Rasmus Grønfeldt Winther, 2015), of time and of space. Then we need to accept that this field would exert a force instantly to every body of mass placed inside that field. The existence of that instant force was a point that finally led to the replacement of the gravitational field with the idea of curved spacetime. The Theory of Relativity stated that there was no way a signal or a force could be transferred 'instantly', given that the speed of light posed a limit to that interaction (Pierre Fleury, 2018). Therefore, curved spacetime came into play. This curved spacetime in the eyes of Einstein was what caused planets to move. As already mentioned, the phenomena stayed the same. Yet, the theory explaining them was utterly different from the previous one: In the new theory of relativity there is no field whatsoever, no instantaneous force, no absolute space and time. Just curved spacetime within the context of relativity.

In other words, the explanation (theory) is not only dictated by the evidence on which it is based upon; we already saw how the same evidence could provide support to different (and even conflicting) explanations. This is not limited to one area but it is an inherent part of the nature of science per se. In future it might well be that the Theory of Relativity will be replaced by another theory (and indeed, since this is the way science works, we can safely predict that this will happen) that will have an entirely different notion as the basis of gravity. In all cases, what all those contradicting theories have in common is that they explain the same phenomena. And the latter gives to outside observers the illusion that the theories are similar - if not in their calculations ${ }^{2}$ at least in their essence, something that is fundamentally wrong as portrayed above.

\footnotetext{
${ }^{1}$ It is important to keep on using the proper nomenclature: Phenomena instead of 'facts'. The former is what we observe. The latter refer to an ideal form of objective reality many philosopher - and even scientists - deny its existence.

${ }^{2}$ In any case, the calculations of any theory can be improved to fit better with the data, regardless of the theoretical background explaining the phenomena. It is just that when a new theory comes along, the old theories are rarely (if ever) updated accordingly and, thus, appear outdated. This could be misleading and has nothing to do with their actual fitness for purpose. The equations of Newton do not have any inherent inability to provide proper results due to insufficient theoretical reasoning; they can just as easily be fitted
} 


\subsubsection{Quantum mechanics and possible interpretations}

Staying in the realm of physics, we can find numerous other examples of how contradicting theories can be built based on the same observations but on different assumptions. Modern particle physics is a good example. The Standard Model shows how basic assumptions are turned into the main founding blocks for theories and how these theories can change in an instant if these assumptions are assumed wrong.

The currently accepted Standard Model of the cosmos is based on the idea of point particles. A point particle is a geometric concept with discrete feature, and its typical representatives are point mass and point charge. Quantum theory - yet another pillar of modern physics - builds on that concept further on and uses the idea of wave particles as its core assumption. Wave particles are figment with both wave and particle features (Z. C. Liang, 2019) and within quantum theory they behave in many unintuitive ways.

To deal with the weird implications of observed quantum phenomena, scientists came up with many interpretations of quantum mechanics (Peter J. Lewis, 2020) (Graham P. Collins, 2007), but not one of them has gained the level of confidence that humanity once had placed on the axioms of Euclid. It is noteworthy to mention that these interpretations are incompatible with one another or even contradicting one another (Graham P. Collins, 2007). From the classical Copenhagen interpretation to the Many-Worlds interpretation, there are multiple ways to explain the observed quantum phenomena. Besides the abovementioned different interpretations of quantum physics, it is also important to know that there are other theories that propose a completely new way of looking into things altogether. So for example in the case of particles, there is a theory which claims that particles are in fact not at all what the Standard Model says they are, but instead one-dimensional objects called 'strings' ("String theory", 2020).

As in the case of gravity, we see the same pattern emerging: One set of universally observed phenomena, but multiple different theories attempting to explain them. A disturbing truth is coming into light as one examines more and more such examples. A truth that destroys the ideal picture we have in mind regarding the relationship between science and reality, by showing how assumptions dictate the theories regardless of the facts and evidence ${ }^{3}$ at hand. The facts anyway have to be respected, since they are the starting point of everything. But the theories change when the assumptions change. Based on the same facts and evidence there can be more than one theories that fit the data. Theories that are built upon different assumptions, which are then in turn questioned by other (newer) theories. The multiplicity of theories and interpretations mentioned in this chapter is not a temporary flaw in our understanding of the cosmos that we will someday resolve, but an inherent limitation of the way science works. As long as you have to start your analysis from assumptions, your theories will always be subject to debate by someone else who uses different assumptions than you.

As I will show below however, there are some assumptions that are more fundamental than others. These are the assumptions which form the basis of science itself and the realm from which they emerge is anything but scientific.

\subsection{Principles of science's principles}

Having established that there are many principles (axioms) that are used to build scientific theories, the next step is to try to explore whether there are any assumptions that transcend all scientific theories, in

to the new observations and be adjusted to fit with the new data we have (regarding the speed of light etc). However scientists are reluctant to perform such work and rightfully so, for practical reasons. If everyone in the scientific community is doing research on the latest theory available, why spend time to update the 'old' one? The hasty world of research today does not allow space for such work.

${ }^{3}$ By 'facts' and 'evidence' we refer to anything we perceive with our senses. This may well be completely invalid or insufficient to describe reality, but that is a philosophical question that is currently unanswered and beyond the scope of this paper. 
the sense that they are more global and universal than others. What is of interest here are the basic principles that make the other principles (and thus science) even possible. If one could envisage a hierarchy of principles, then the principles presented in this section are the 'principles of principles' of modern science. Without those, there would be no way to even formulate other principles or axioms, in order to start building new theories. Knowing these assumptions is of high importance, since they are connected to the very essence of science per se. Exploring them will lead to a greater and deeper understanding of science.

\subsubsection{The comprehensibility of the cosmos}

When people speak about science, they usually omit the most obvious of principles on which science is based upon: The (seemingly unfounded) belief that the cosmos is comprehensible. People use to quote Einstein on saying that the most incomprehensible thing about our cosmos is its comprehensibility (James B. Hartle, 2016). However the actual expression used by Einstein was much more 'religious' in nature. Einstein actually wrote in a U.S. science journal in 1936 that "The eternal mystery of the world is its comprehensibility... The fact that it is comprehensible is a miracle". (Andrew Robinson, 2016) This comprehensibility or - to be exact - our faith in it, lies in the foundations of science in all its aspects, common to both the Scientific Revolution and the Enlightenment (Steve Fuller, 2008, p. 5). The assumption that the world is (rationally) intelligible transcends all scientific enterprise (Alan Thomas, 2018) and without that assumption (call it an 'axiom' or a 'principle' and the essence will not change) there is no point in even starting to analyse the cosmos with scientific tools. If one could state which is the most fundamental assumption used by all science sectors and all scientists regardless of their field of expertise, this would be it.

It is so fundamental that one does not even think of it. But it is there. Buried under every scientific endeavour. Almost tautological in nature ${ }^{4}$, it transcends all efforts of the human intellect to make sense of the cosmos and to comprehend its workings. And this is logical in every sense. One does not start walking unless he believes he will reach his destination. One does not start analysing gravity or the physics of particles unless he firmly believes that his efforts will result in something. Such a fundamental principle does not require more analysis or elaboration for it is self-explanatory. Yet, it is still not sufficient to explain science. For the scientist to get out of bed and start experimenting, something more is needed.

\subsubsection{Our ability to comprehend the cosmos}

The acceptance (by faith) of the comprehensibility of the cosmos may provide a potential goal, but this is not sufficient by itself to make someone start building science. For even if something is possible, this does not mean that it will happen as well. One also needs to believe that he is capable of reaching that something as well. It is not enough that the cosmos is comprehensible. In order to embark on a journey to understand it and explain it, we need to believe that we are able to attain the comprehension the cosmos offers. In other words, if we are to start building theories to explain the universe, we need to believe that we are capable of building those theories - they will not be built by themselves.

Again, this assumption is so self-evident and tautological in nature that it sounds almost paradoxical to speak about it. But if we are to break down the required assumptions for doing science, this belief into our ability to make science is necessary. The possibility of science happening is not enough. We must have - or at least believe that we have - the capability of developing that science. This faith is instilled in everything science tries to achieve today; evident in the efforts of scientists to understand the universe, present in the efforts of researchers to understand the human brain, obvious in our efforts to explain the very existence of the cosmos. We are making science because we believe we can make science.

This second assumptions completes the list of fundamental assumptions needed to start conducting science. After taking these two assumptions for granted, the road is open for analysing specific phenomena,

\footnotetext{
${ }^{4}$ Tautology could be the only valid form of knowledge, which needs no assumptions to be considered true. However, the analysis of this very important topic is beyond the scope of this paper.
} 
formulating scientific models to explain them and trying to reach a theoretical understanding of their nature. This paper will focus on those two basic assumptions - although it is needless to say that the epistemology of all other principles used by science in its various fields is a topic of immense importance.

The next element to examine is how we came to believe into the above assumptions. What drove us into accepting them and, thus, allowing us to start being scientists in the first place? The results of this analysis will show that the cause of our belief into these assumptions is unscientific and at the same time hugely religious in nature, at least as per the modern way of defining science.

\subsection{Reading the mind of God}

The quest to find out how humans started believing (or accepting) the two principles described above as the pillars of science, leads to religion. Because it is religion that offers us faith in the importance of man. Without believing in our importance, it would be laughable to even consider the possibility that we have the ability to create theories, let alone comprehend the cosmos. The belief that we can comprehend the universe is based on two major Christian assertions: The belief that we are made in the image of God (Matt Stefon, Geoffrey Wainwright, Carter H. Lindberg, William Richey Hogg, Henry Chadwick, ..., Linwood Fredericksen, 2020) and essentially part of Him (Mark Shuttleworth, 2020) (Lossky, Vladimir, 2002) (Athanasius of Alexandria, 2011) ${ }^{5}$ and the belief that, consequently, we can comprehend how His mind works.

This was the main idea behind every scientist's mind up until very recently in human history. As Newton said, "This Being governs all things, not as the soul of the world, but as Lord over all: And on account of his dominion he is wont to be called Lord God $\pi \alpha v \tau$ скра́ $\tau \omega \rho$ or Universal Ruler" (Newton, 1729).

It is not just that if we exclude God from the definition of science then, in one swoop, we exclude the greatest natural philosophers of the so-called scientific revolution - Kepler, Copernicus, Galileo, Boyle, and Newton to name just a few (Helen De Cruz, 2017). Faith in God was important not only due to social or personal reasons. It was of paramount importance for the actual scientific work of these men as well. So deeply rooted is that belief that even so-called agnostic or atheistic scientists cannot escape referring to the same faith when making science. For example, one of the most famous pages of the well-known book "A Brief History of Time" by Stephen Hawking is that in which the writer speaks of an imminent "theory of everything' and claims that such a theory would allow us to know "the mind of God" (Stephen W. Hawking, 1988). For Hawking, an agnostic, the phrase is supposedly little more than a metaphor (at least for his

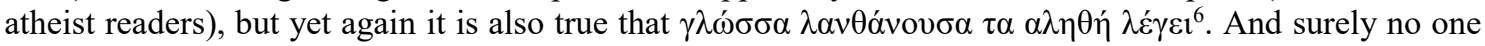
else can interpret what he meant but himself, who for a long time disliked the label "atheist" (Karl Giberson, Mariano Artigas, 2007) ${ }^{7}$, even though at the end he started to identify as such.

Hawking aside, one can trace the importance of believing that we can read the mind of God in the thought of all prominent scientists especially in the early era of modern scientific endeavour. To the eighteenth-century mind, the whole world seemed to be evidence of God's special provisions. God had provided the Earth with an atmosphere with the intention of allowing men and animals to breathe. He had

\footnotetext{
5 "I said, You are gods, and all of you are children of the Most High" (Psalm 82:6) In the Orthodox Church, the concept of humans being god is neither new nor startling. It even has a name: theosis. Theosis is the understanding that human beings can have real union with God, and so become like God to such a degree that we participate in the divine nature. Also referred to as deification, divinization, or illumination, it is a concept derived from the New Testament regarding the goal of our relationship with the Triune God. [AA16] As Athanasius of Alexandria wrote, "He was incarnate that we might be made god" (Aủtòs yò

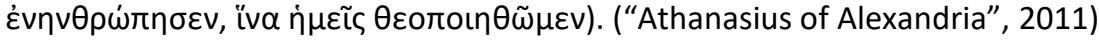

${ }^{6}$ Logos which refers to something by mistake, speaks the truth.

${ }^{7}$ To provide the full picture, it must be noted that this changed during the latest stages of his life though, where he declared that there is little or no possibility of God into our universe (Brandon Specktor, 2018).
} 
created humans with complicated organs whose purposes were evident, but whose workings were obscure. Kant quite understandably wanted to save God the trouble of making special provisions for each plant and animal, and argued for the possibility of an overriding system of physical law that could result in the world of living organisms that we know, without the need of innumerable particular divine interventions (Roger Caldwell, 1995).

The overall point is that, despite the details, in all cases of scientific thought the idea of a God penetrates everything - either consciously or unconsciously, but always essentially. Overall, humans believe that they can understand the cosmos only because they believe in the idea of them being created as creatures in imago dei. Thus, nature is intelligible for them (Steve Fuller, 2008, p. 5). The cosmos is not considered as something foreign but as a place on which we can exert our mind to make sense of. And even though we were temporarily cast out of heaven, we are still His sons. And as the sons of God, we can understand Him, so that we can eventually reach Him again.

Going back into the first years of modern science is important can help us understand and appreciate the nature of the issues we are dealing with here. The birth of science in the womb of religion was a very important milestone in human intellectual history that we often and easily (perhaps also knowingly) tend to ignore.

\subsubsection{The birth of a new child}

If we are to understand the true nature of science, we must go far beyond Newton and Leibnitz (who also had God as a cornerstone of his science, refer to Brandon C. Look, 2013), to the beginning of science as we know it today. From ancient Greece up to the time before Thomas Aquinas, science and religion were not separated. At some point though, something happened which separated the two realms of knowledge and gave birth to what we know today as modern science. Understanding how this happened is important to gain an understanding of the character of this new child of human intellect.

There is a lot of discussion on how modern science was born. For many, the birth date is 7 March 1277, when Bishop Tempier condemned a great number of "errors" from teachers. The condemnation sought to stop the Master of Arts teachers from interpreting the works of Aristotle in ways that were contrary to the beliefs of the Church (Condemnations of 1277, 2020). Among the theses condemned were sixteen of Aquina's theses (J.J. Chambliss, 2013). There is much debate on the significance of this event (Hans Thijssen, 2018). For many, this denoted the separation of theology from natural sciences, where the latter where deemed incompatible with the wisdom of the scriptures. Others claim that this event freed up Christianity from the dogmatic Aristotelian view of the cosmos. Other believe that Thomism allowed the two schools or realism and idealism to agree to disagree to the extent that in the graduate curriculum of the university, natural philosophy could be taught apart from theology. This separation of secular or natural philosophy from theology opened the way for the development of the empirical sciences. The disparities between these two separate ways of knowing were resolved, not by compartmentalizing them into separate domains, but by proving the domains to be philosophically complementary, creating a holistic framework in which we could reconcile apparent conflicts between theology (religion) and natural philosophy (science) (Kondrick LC, 2008). Others believe that Tempier's condemnation was a symptom of the existence of rationalist currents at the University of Paris, in the sense of the emergence of philosophy as an autonomous discipline vis-à-vis divine revelation, has been further developed by scholars such as Alain de Libera, Kurt Flasch, and Luca Bianchi (Hans Thijssen, 2018).

The details of what really happened are mute. What is certain is that science was born; science that we use today as a separate domain of thought, different than that of religion. Before a point in time, religion and science were not separated, but from that point onwards science as we know it today started following its own separate path. Going forward some centuries, the next important milestone in the life of modern science is the time when it reached adulthood. And even if the exact date of birth of science is a matter of debate, most would agree that the date when science reached adulthood can be placed with the era of the Galileo trial and its implications on how science stood up against its own parent. Again, the details are 
insignificant in the face of the actual facts ${ }^{8}$. What is important is that from a point onwards the child became a parent, after killing its own father. And from Galileo's time onwards, science dictated terms in its relationship with religion.

This philosophical separation resulted in the scientists forgetting what was the real reason they do science. They still kept looking for answers, but without religion they had forgotten why they even do it. And in order to compensate for this lost knowledge, they needed to add the foundations to their structure as assumptions. The child was orphan now. And to explain its existence, it needed to invent its parents. The only problem is that when you decide the destination on your own, it is easy to change destination at your own free will. When there is no compass, the final destination is never certain.

\subsubsection{Killing our Father (From Understanding to just Knowing)}

As a spoiled child, modern science tries hard to get free of the "bondage" of its true father. In its effort to do so, it has created a fantasy of a cosmos that is intelligible (if it was not, there would be no science) but with no reason at all. In its effort to do so, it has created a cosmos where humans are able to understand the cosmos (if they could not, there would be no reason to strive for science), but again for no apparent explanation for that wonder.

The phrase of Einstein about a "miracle" starts now to reveal its true meaning. With religion around, trying to find answers for how the cosmos works did not require any special explanation. It was simply part of the knowledge we were destined to acquire as children of God and as parts of the cosmos itself. But in an era without religion, in an era were God is dead (only because we killed Him as Nietzsche said), the mere action of doing science is absurd. Why search for answers in a cosmos ruled by randomness? Why do science if there is no reason to believe that you can understand the cosmos? In an era without religion, we desperately need the assumptions described in the sections above, while in the years when science was not separated from religion, there was no need for such assumptions since they were embedded in the way humans thought in the first place. Not as assumptions or principles but as facts of life; facts based on the faith on something bigger than life itself as Rilke used to say. And as weird as it may sound, today, in an era when we do not believe in miracles, we do science only because of them.

The ripples of the religion and science separation do not stop at why we do science. The removal of God's Logos from scientific effort made also science void of any true meaning. That is the reason why science gradually turned from philosophy to a simple data gathering exercise. As Levy Bruhl correctly pointed out, science turned from understanding to just knowing (Wilbur M. Urban, 1924). And the story of science turned from a tragedy into a farce. Because knowing is nothing more than an illusion; with different assumptions we can easily 'know' completely different things than the ones we currently do. In a science based on nothing more than miracles, there is nothing to stop us from believing in some other kind of miracles and, thus, changing course to another direction altogether. In the post-modern era when people constantly doubt about everything, there is nothing to stop science from doubting its own existence. Funnily enough, this was not even possible when religion was the dominant way of thinking in Europe.

千里之行, 始於足下 (A journey of a thousand miles begins with a single step) $\sim$ Lao Tzu, Tao Te Ching

\subsection{Why do we do science?}

We have almost reached the end of the road. Having established why the cosmos is intelligible and why we can grasp that intelligibility, we are yet one small step away from fully explaining the existence

\footnotetext{
${ }^{8}$ For Galileo one can find a detailed account on how he was scientifically and philosophically wrong in defending his views the way he did, in the article "From Galileo to Hubble: Copernican principle as a philosophical dogma defining modern astronomy", International Journal of Theology, Philosophy and Science 2 (3), 13-37 (S. Kakos, 2018).
} 
of science. Because even after taking all of the above for granted, the question still remains. Why do we do science anyway? Even if the world is intelligible and even if we can understand it, why do we choose to do so? A question so simple and yet - as every simple question - hard to answer. Knowing why this happens provides an additional insight on the relation between religion and science, at an even more essential level than the one mentioned already.

We can only reach that level if we see beyond the details of epistemology, details that do nothing but obscure the real question we should try to answer. Behind the surface of trying to comprehend a cosmos and of believing that we can achieve that comprehension, there lies something more fundamental: A basic need for knowledge per se. Science is accepted and used on the very practical basis of fulfilling that basic need to understand and know. Our belief that the cosmos can be understood and our belief that we can achieve that knowledge, only come as a consequence of our most basic initial need for knowledge as such. A need that existed long before we had the tools to attain it

In other words, if our belief that we can answer our questions for the cosmos is the basis of us using science, us having those questions is the reason we begun the journey of science in the first place. Our fundamental need to know, is translated in religion as our need to reach theosis. This was a need that existed for Christians aeons before science came into the scene as an independent realm of human intellect and translated this need for theosis in the need to acquire knowledge. This more fundamental element missing to answer why we do science has been lying in the foundations of religion for millennia now: It is our need to reach God.

And the only reason humans dare to start this journey is because they believe they occupy a privileged position in the cosmos, something evident in the creation accounts of religion. In Christianity, Judaism, and some strands of Islam, humans are created in the image of God. There are at least three different ways in which this image-bearing is understood. According to the functionalist account, humans are in the image of God by virtue of things they do, such as having dominion over nature. The structuralist account emphasizes characteristics that humans uniquely possess, such as reason. The relational interpretation sees the image as a special relationship between God and humanity (Helen De Cruz, 2017). In any of those cases, the result is essentially the same: this special relationship between man and God is what drives the former to start a journey towards the latter. And the first step is the most important part of any journey.

It is weird that so many articles on the matter fail to see and examine the obvious question lingering in science from the beginning: even if we are able to understand the universe, even if the universe is comprehensible and able to be understood, why would someone start the journey towards that understanding? Mere curiosity is one way to explain this; however, this would reduce thousands of years of philosophy to a mere caprice. And would make the non-development of science as logical as the current path we have chosen. But could we ever imagine a world without science? In a world full of God, there is only one destination we could choose. And that is towards achieving a union with Him. That is the only meaning one can ever find in science and the only goal science can ever strive for; for if we are to accept that the cosmos is void of anything meaningful then there is no reason to disembark on any journey even though we know we can.

"If we do discover a theory of everything... it would be the ultimate triumph of human reason, for then we would truly know the mind of God" $\sim$ Stephen Hawking, Brief history of Time

\section{CONCLUSION}

When Jesus Christ came back to Earth after His resurrection, He visited his students for the last time. What did He offer as this last appearance? Did He offer any great philosophical quote for us to remember Him by? Did He provide any deep spiritual piece of wisdom for us to ponder upon? Perhaps He gave us a hint on how to understand and decipher the secrets of the cosmos? No. He just asked them "Are 
you catching any fish?". And the students answered "No". And He helped them. And then He prepared food for them. "Come and have breakfast" He told them (John: 21). And they came.

This very simple story reveals the common ground not only between religion and science but between all types of human endeavour in general. We have specific needs and these basic needs are those which govern our lives from the moment we started walking on this Earth. Our need is to eat. And grow. Our need is to know. And become part of God. It is just that we are progressing too fast to realize that we might be wandering off course, our arrogance making it impossible to know that we are astray. We will eat the apple. Not yet though.

Heisenberg was famous to note that "The first gulp from the glass of natural sciences will turn you into an atheist, but at the bottom of the glass God is waiting for you". Newton had certainly reached that point when he wrote about gravity that "Gravity must be caused by an agent acting constantly according to certain laws; but whether this agent be material or immaterial, I have left open to the consideration of my readers" (Andrew Janiak, 2006). In his theory, as in every other scientific theory, something is ever-present beyond the words written on paper. Something beyond the plain numbers and scientific models. Something that could explain the existence of science per se - and why we would even start drinking from the glass of science to begin with.

Science is not a way towards God nor a path away from Him. It is God himself speaking to us. Look at the most basic assumptions of every theory, any scientific paper. And beyond the words of children who have been lost for a long time, you will recognize their agony that one day they will return home. For unlike religion that has God as its ultimate goal, science has God as its sole starting point. And when we reach the bottom of the glass, He will lovingly remind us the obvious. "You wouldn't be searching for Me if you hadn't already found Me"...

\section{BIBLIOGRAPHY}

[1] Alan Thomas, (2018), Intelligibility all the way down: Interpreting Nagel's Mind and Cosmos, Klesis Revue philosophique, Vol. 41, 01.08.2018, p. 1-29, retrieved from https://www.revueklesis.org/pdf/Klesis-41-Nagel-09-Alan-Thomas-Intelligibility-Interpreting-Nagel-s-Mind-andCosmos.pdf on 2020-01-07.

[2] Andrew Janiak, (2006), Newton's philosophy, Stanford Encyclopedia of Philosophy, retrieved from https://plato.stanford.edu/entries/newton-philosophy/\#AftPriIIDebLei on 2019-12-15.

[3] Andrew Robinson, (2016), We Just Can’t Stop Misquoting Einstein, Prime Mind, retrieved from https://primemind.com/we-just-cant-stop-misquoting-einstein-19ad4efab26e on 2019-12-12.

[4] Athanasius of Alexandria, (2011), On the Incarnation of the Word. Popular Patristics Series. 44. Translated by Behr, John. Yonkers, New York: St Vladimir's Seminary Press. ISBN 978-0-88141427-1.

[5] Brandon C. Look, (2013), Gottfried Wilhelm Leibniz, Stanford Encyclopedia of Philosophy, retrieved from https://plato.stanford.edu/entries/leibniz/\#ExiGod on 2020-04-10.

[6] Brandon Specktor, (2018), Stephen Hawking's Final Book Says There's 'No Possibility' of God in Our Universe, Livescience, October 17, 2018, retrieved from https://www.livescience.com/63854stephen-hawking-says-no-god.html on 2020-01-03.

[7] Condemnations of 1277, (2020), Wikipedia article, retrieved from https://en.wikipedia.org/wiki/Condemnations_of_1210\%E2\%80\%931277 on 2020-01-07.

[8] Graham P. Collins, (2007), The Many Interpretations of Quantum Mechanics, Scientific American, November 19, 2007, retrieved from https:/www.scientificamerican.com/article/the-manyinterpretations-of-quantum-mechanics/ on 2020-01-03. 
[9] H. G. Forder, (1929), The Axioms of Geometry, The Mathematical Gazette, Vol. 14, No. 199 (Mar., 1929), pp. 321-331, Published by: The Mathematical Association, DOI: 10.2307/3606716, retrieved from https://www.jstor.org/stable/3606716 on 2020-01-03.

[10] Hanne Andersen, Brian Hepburn, (2015), Scientific method, Stanford Encyclopedia of Philosophy, retrieved from https://plato.stanford.edu/entries/scientific-method/ on 2019-12-26.

[11] Hans Thijssen, (2018), Condemnation of 1277, Stanford Encyclopedia of Philosophy, retrieved from https://plato.stanford.edu/entries/condemnation/ on 2020-01-07.

[12] Helen De Cruz, (2017), Religion and Science, Stanford Encyclopedia of Philosophy, retrieved from https://plato.stanford.edu/entries/religion-science on 2019-12-12.

[13] J.J. Chambliss, (2013), Philosophy of Education: An Encyclopedia, p. 640.

[14] James B. Hartle, (2016), Why Our Universe Is Comprehensible, Department of Physics, University of California, retrieved from https://arxiv.org/pdf/1612.01952.pdf on 2019-12-12.

[15] Karl Giberson, Mariano Artigas, (2007), Oracles of Science: Celebrity Scientists versus God and Religion, Oxford Scholarship Online, DOI: 10.1093/acprof:oso/9780195310726.001.0001, retrieved from https://www.oxfordscholarship.com/view/10.1093/acprof:oso/9780195310726.001. 0001/acprof-9780195310726-chapter-3 on 2020-01-03.

[16] Kondrick LC, (2008), Thomism and science education: history informs a modern debate, Integr Comp Biol. 2008 Aug;48(2):202-12. doi: 10.1093/icb/icn059. Epub 2008 Jun 21., retrieved from https://www.ncbi.nlm.nih.gov/pubmed/21669784 on 2020-01-03.

[17] Lossky, Vladimir, (2002) [1957], The Mystical Theology of the Eastern Church. Crestwood, New York: St. Vladimir's Seminary Press. ISBN 978-0-913836-31-6.

[18] Marco Giovanelli, (2004), Einstein's Philosophy of Science, Stanford Encyclopedia of Philosophy, retrieved from https://plato.stanford.edu/entries/einstein-philscience/ on 2019-12-12.

[19] Mark Shuttleworth, (2020), Theosis: Partaking of the Divine Nature, Antiochian Archdiocese, Conciliar Press, retrieved from http://ww1.antiochian.org/content/theosis-partaking-divine-nature on 2020-01-03.

[20] Matt Stefon, Geoffrey Wainwright, Carter H. Lindberg, William Richey Hogg, Henry Chadwick, ..., Linwood Fredericksen, (2020), The human as the image of God, Encyclopaedia Britannica, retrieved from https://www.britannica.com/topic/Christianity/The-human-as-the-image-of-God on 2020-0103.

[21] Newton, (1729), The Mathematical Principles of Natural Philosophy.

[22] Peter J. Lewis, (2020), Interpretations of Quantum Mechanics, Internet Encyclopedia of Philosophy, retrieved from https://www.iep.utm.edu/int-qm/ on 2020-01-03.

[23] Pierre Fleury, (2018), Gravitation: From Newton to Einstein, Lectures given at the African Institute for Mathematical Sciences, Cameroon (AIMS-Cameroon), in January 2018 and January 2019, retrieved from https://arxiv.org/pdf/1902.07287.pdf on 2020-01-30.

[24] Rasmus Grønfeldt Winther, (2015), The Structure of Scientific Theories, Stanform Encyclopedia of Philosophy, retrieved from https://plato.stanford.edu/entries/structure-scientific-theories/ on 2019-1227

[25] Roger Caldwell, (1995), Reading the Mind of God, Philosophy Now, retrieved from https://philosophynow.org/issues/13/Reading_the_Mind_of_God on 2020-01-03.

[26] S. Kakos, (2018), From Galileo to Hubble: Copernican principle as a philosophical dogma defining modern astronomy, International Journal of Theology, Philosophy and Science 2 (3), 13-37.

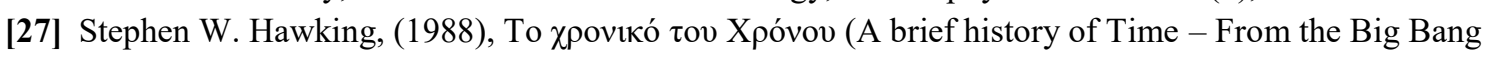

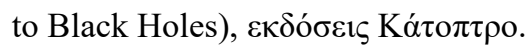


[28] Steve Fuller (2008), Dissent over Descent, Icon Books.

[29] String theory, (2020), Encyclopedia Britannica, retrieved from https://www.britannica.com/science/string-theory on 2020-03-08.

[30] Tomas Kala, (2019), Remarks to Gravitation Theories, Journal of Physical Science and Application 9 (2) (2019) 26-29, doi: 10.17265/2159-5348/2019.02.004, retrieved from on 2019-12-20.

[31] Wilbur M. Urban, (1924), The Intelligible World (I), The Philosophical Review, Vol. 33, No. 1 (Jan., 1924), pp. 1-29 (29 pages), Duke University, retrieved from https://www.jstor.org/stable/2178881 on 2020-01-07.

[32] Z. C. Liang (2019), Modeling of real particles, 8th International Conference on Mathematical Modeling in Physical Science, Journal of Physics: Conference Series 1391 (2019) 012026, IOP Publishing, doi:10.1088/1742-6596/1391/1/012026, retrieved from https://iopscience.iop.org/article/10.1088/1742-6596/1391/1/012026/pdf on 2019-12-20. 